J OURNAL OF French and Francophone Philosophy
RE V UE DE LA

philosophie française et de langue française

\title{
The Question of Re-turning: Toward or Away from the Virtual?
}

Sanja Dejanovic

Journal of French and Francophone Philosophy - Revue de la philosophie française et de langue française, Vol XXIII, No 1 (2015) pp 79-101.

\author{
Vol XXIII, No 1 (2015) \\ ISSN 1936-6280 (print) \\ ISSN 2155-1162 (online) \\ DOI 10.5195/ jffp. 2015.682 \\ www.jffp.org
}

\section{(c) EY-NC-NO}

This work is licensed under a Creative Commons Attribution-Noncommercial-No Derivative Works 3.0 United States License.

\section{UILIS D-Sult}

This journal is operated by the University Library System of the University of Pittsburgh as part of its D-Scribe Digital Publishing Program, and is co-sponsored by the University of Pittsburgh Press 


\title{
The Question of Re-turning
}

Toward or Away from the Virtual?

\author{
Sanja Dejanovic
}

Trent University

In an interview "On Philosophy" included in Negotiations (1995), Gilles Deleuze remarks: "I've tried in all my books to discover the nature of events; it's a philosophical concept, the only one capable of ousting the verb 'to be' and attributes." 1 It is by now generally understood that the nature of events are central to Deleuze's philosophical endeavour. This has not meant, however, that the process mapped out by this concept has been adequately grasped. Indeed, the lines mapping out events are obscured, theoretical, even otherworldly, whenever the complexities of the creating of the virtual and the actual as the created, are reductively conceived as giving way to two separated domains; two separated domains whereby the repeater would be forever condemned to be the result of an otherworldly will that "works through it," one that would signal that they would never be capable of becoming worthy of the events that make a life. ${ }^{2}$ The perspectival reality of the virtual with respect to the actual, which despite its fragmentary nature is in its entirety encompassed in each singular event, requires of us that we grasp what it is that Antonin Artaud's points to when saying, I "am my son, my father, my mother, and myself." It is not as though events perceived in the form of a virtual complex render beings inconsequential; instead, events are capable of ousting the verb "to be" in a double sense, because they enfold what is most affirmative in the activity of beings, the being of becoming whereby a life is born, always yet again, and as a function of which, as Alfred North Whitehead notes, what an actual being is, is how that entity becomes. It is adequate to its becoming. The actual as presentbeing expresses the verb "to be" in an ephemeral sense, or it is expressed by it in a restrictive way, while when affirmed as indistinct from the virtual, being, the verb "to be," implies nothing else than the return of becoming. It is an untimely instant in which what is affirmed is the continuation of becoming; an instant that makes each event be the infinite becoming-finite of an actual being. So as to explore the nature of events in Deleuze's 
philosophy, it is this displacement, the ousting of the verb "to be," that I focus in on in this paper.

The ousting of the verb "to be" is owed most of all to Nietzsche's eternal return, which has a prominent place in Deleuze's philosophy as the empty form of time, what he calls a pure event enfolded in every event, since it is with respect to it that all time unfolds simultaneously. It unfolds as a double movement that defines the nature of events, one that is taken up in the title of this paper under the guidance of the question, toward or away from the virtual. As we will see, the being of the question does not play a trivial role in the nature of events, rather, it is a threshold, a borderline, a frontier, marking a differentiation that opens up the double movement enfolded in each event. Indeed, without the being of the question, which, as noted, signals the return of differentiation, ${ }^{3}$ what we would be left with is the being of the past, the ground of actuals, which appears to uphold a duality of the virtual and the actual. To be installed in, or to turn toward the being of the past, does not mean that the nature of events has been secured. The being of the past, as Deleuze tells us, is vulnerable to becoming appropriated by representational models which reinforce the verb "to be." This is precisely why the nature of events must be sought after from the perspective of a re-turning, which I have framed here as one of orientation toward or away from the virtual for the purposes of pointing to the double directionality of events. In other words, with the question, I am emphasizing two simultaneous yet dissymmetrical processes in Deleuze's philosophy, the actualization of the virtual which is reflected in the ground as the potential of a singularized event, and the counter-actualization of the virtual, with respect to which the status of the actual becomes otherwise. It is not as though one of these processes is the correct one, while the other one illusory. Rather, this double optics, the turn from one to the other, is decisive in the discovery of the nature of events. Of course, the being of the question expressed as the question of re-turning invokes much more than this; it invokes a selective test, one in which to turn toward the virtual, yet again, is to comprehend that which is repeated in the repetition of the virtual events of the past. It is to grasp how it is that the nature of all events, this event too, can be adequately conceived from the perspective of the pure event itself. What is conceived is the double movement, the double optics, to and from the virtual, which defines events, and displaces the verb "to be" in both of the senses discussed.

This double optics has not only been the abiding source of the philosophical endeavour, it is also the terrain that gives way to much dispute preoccupying thinkers. As I have noted, the questioning, which properly speaking invokes a re-turning, has been traditionally posited in the form of the question, what is the object=x. Or, to take one reference point, Husserl posits such questioning as a reorientation of vision, as a shedding light on how an object becomes determinable from the perspective of the 
noematic complex, once the stream of consciousness has been exhausted in copulative spontaneity. 4 Said otherwise, the re-turning, to which questioning most intimately belongs, presents the instance in which the horizon of grounding prompts another optics; one that does not simply expose what a being is but how it becomes determinable to begin with. We might even say, at the least with respect to Deleuze's philosophy, that with re-turning, the question of the how not only takes precedence, but that it exposes the nullity of the question what is $x$ posited for itself. As mentioned, Whitehead is admired as a philosopher of the event by Deleuze, precisely because for him, "how an actual entity becomes constitutes what that actual entity is." 5 Such an articulation in which the how has primacy, only becomes possible with the reversal or inversion of the processes that seem to correspond to these questions. By turning to Nietzsche, Deleuze effectuates such a reversal when claiming that what can be said of being is becoming, or that being is itself becoming. This is the univocity of being. The problem here, as we will see in the first section of this paper, is that the eternal return, which is the heart of the event, must at once be continuation and moment. In other words, the displacement of the verb "to be" hinges on the articulation of the eternal return as continuity of becoming, and the break in the stream of the coming-to-be. Once I have explored this core aspect of Deleuze's ontology, I will delve into the double lines of articulation, the movements toward and away from the virtual that define the nature of events, by placing the emphasis on the syntheses of time. Since time is not internal to beings, but beings are internal to time, it is only from the perspective of the flow of time that we can manage to think how a being becomes what it is, without reducing such a being to an identity that subjugates it in actuality.

\section{Ousting the Verb "to be" with Nietzsche}

To adequately conceive of the creating of the virtual and the actual as the created, one need be equipped with a comprehension of the univocity of being that Deleuze furthers. According to him, the three thinkers in the history of philosophy that have advanced the univocity of being are Duns Scotus, Spinoza, and Nietzsche. Indeed, Spinoza charts one of the best planes of immanence precisely because he does not hand over immanence to anything transcendent. ${ }^{6}$ However, as he notes in Difference and Repetition (1968), while Spinoza affirms univocal being, it is Nietzsche who effectively realizes it with the eternal return. His rationale for favoring Nietzsche's approach with respect to the univocal being is clearly delineated in that text, where he writes: "There still remains a difference between substance and the modes: Spinoza's substance appears independent of the modes, while the modes are dependent on substance, but as though on something other than themselves. Substance must itself be said of the modes and only of the modes."7 It is said of the modes, and, is in turn, made inconsequential, insofar as it is expressed in the form of Nietzsche's eternal return. In other 
words, all creating of the virtual must be approached from the perspective of the eternal return, which is the pulse of Deleuze's philosophical endeavour. What I intend to do here is to show how Nietzsche's eternal return realizes the univocity of being, by focusing in on the role Nietzsche plays in Deleuze's efforts to displace the verb to be. While I cannot take up Deleuze's overturning of Platonism here, it is the common root that binds him to Nietzsche in his endeavour to displace the verb to be. Equally, whether or not Nietzsche actually overturned Platonism, being Heidegger's question, is something I cannot consider. ${ }^{8}$ In what way does Nietzsche, however, set out to overturn Platonism, or, more specifically, the antinomy of being and becoming? In "The Overturning of Platonism and the New Meaning of Appearance," Michael Haar presents the sequential development of the problem in Nietzsche's thought. In some of his earliest writings, Nietzsche seeks to displace the notion of the true world by praising the life lived amongst appearance: "My philosophy, Platonism overturned: the further one moves away from true being, the purer, the more beautiful, the better it is; Life in the midst of appearance as goal."9 But in affirming appearance, Haar asks, doesn't Nietzsche nevertheless maintain the antinomy, for what else could appearance be but illusion? Doesn't a life in the midst of appearances reinforce nihilism which revert us to the true being? Nietzsche's answer in The Twilight of Idols is a definite no: "We have rid ourselves of the true world: what world are we left with? Perhaps that of appearances? [...] But no! Along with the true world, we have also rid ourselves of the apparent world."10 Perhaps it is not even a question of overturning the Platonic antinomy, but more so, as Nietzsche notes, of unlearning it. Isn't the one who is capable of living life amidst appearances, skimming the surface or skin depth of things, the one who has indeed unlearned it? Once we put aside the antinomy, what do we have left? We have a being whose goal is the willing of the endless return of appearing. No longer resenting the passage of time, only such a being is capable of extracting a form from chaos. "To impress upon becoming the character of being - this is the highest form of the will to power. [...] That everything returns - here a world of becoming comes closest to the world of being."11 To realize Nietzsche's eternal return which impresses the mark of being upon becoming, the antinomy must be unlearned.

Nietzsche recognizes the doctrine of eternal return in Stoic teachings, who according to him had inherited the concept from Heraclitus. Nietzsche, for whom Heraclitus plays the role that he himself plays in Deleuze's philosophy, claims that the Stoics had made an "old song" of the eternal return. One can turn to his early work, "Philosophy in the Tragic of the Greeks," in order to grasp the comparison that I have drawn. In that piece, Nietzsche contrasts Anaximander, who had left coming-to-be in the indefinite, to Heraclitus who did away entirely with the duality of indefinite being and definite beings, by cancelling being altogether as separate from the world of becoming. The aim of the two Hellenistic philosophies is 
different, one inquiring into the passing of beings as a sort of atonement for having separated from being, the other testifying to the innocence of existence, of the becoming of beings. A fragment demonstrating Heraclitus' position is too interesting for us to skip over for the sake of brevity: "I see nothing other than becoming. Be not deceived. It is the fault of your myopia, not of the nature of things, if you believe you see land somewhere in the ocean of coming-to-be and passing away."12 But if there is not such land in the ocean of coming-to-be, in what way can the eternal return express that being is becoming? Heraclitus notes that becoming is like the "everlasting wave beat and rhythm of things. And what did I see? [I saw] lawful order, unfailing certainties, ever-like orbits of lawfulness."13 For Heraclitus, this eternal coming-to-be expresses nothing but the world of play, the innocence of creating and dissolving a form, so that we may create once again by starting the game anew. "In this world only play, play as artists and children engage in it, exhibit coming-to-be and passing away, structuring and destroying, without any moral additive, in forever equal innocence. [...] Such is the game that the aeon plays with itself." 14 We can now see why Nietzsche thought that the Stoics, like Zarathustra's caricature, had made an old song of the eternal return. For him, the Stoics had already made a useful doctrine of it; they evaluated the doctrine for the purpose of conceiving a morality. And so, he writes, that the Stoics misinterpreted Heraclitus, "dragging down his basically aesthetic perception of cosmic play to signify a vulgar consideration for the world's useful ends."15

In Nietzsche and Philosophy (1962), Deleuze returns to Heraclitus as Nietzsche's precursor, so as to elucidate what the affirmation of becoming implies, what it means to affirm becoming, and what is affirmed in becoming. The fundamental problem is how to articulate becoming without referring it to something transcendent that would dictate its movement. As Nietzsche frames it, how can we impress the character of being on becoming without returning to the duality of appearance and essence? Taking up this concern, Deleuze writes:

In the first place, it is doubtless to say there is only becoming. No doubt it is also to affirm becoming. But we also affirm the being of becoming we say that becoming affirms being or that being is affirmed in becoming. Heraclitus has two thoughts which are like ciphers: according to one there is no being, everything is becoming; according to the other, being is the being of becoming as such. A working thought which affirms becoming and a contemplative thought which affirms the being of becoming. [...] For there is no being beyond becoming [...]; becoming is the affirmation of being. 16

That being is becoming means nothing more than that being cannot be conceived of as separate from becoming, it is becoming as such. In what sense is it becoming? Deleuze argues that only in its returning is being becoming. ${ }^{17}$ In being affirmed of becoming, being is affirmed for-itself as the 
repetition of becoming. There are two affirmations, or the doubling of affirmation, involved in the realization of the eternal return: the affirmation of becoming and the affirmation of the being of becoming. The two are not separate. When we say along with Deleuze that becoming is affirmed and then that the being of becoming is in turn affirmed, we do not mean that this is their order of production, even if it is their order of presentation. As I will soon show, the eternal return as the synthesis of time that works in reverse forms a single becoming.

Because in Thus Spoke Zarathustra (1883) and other works, Nietzsche refers to the eternal return as a tortuous circle, how is the return of becoming itself not the return of the identical? This is the question to which Difference and Repetition, right to its concluding arguments, serves as a response. The whole of the philosophy of difference is compromised if Deleuze is unable to demonstrate how the eternal return breaks the vicious circle of the return to the identical to then form a line or, as Nietzsche calls it, the "supreme constellation of being." It is not as though philosophies that affirm the identity of the absolute, namely Hegel, do not conceive of such a constellation of being. The problem is precisely that Hegel, from the perspective of Deleuze's thought, imprisons himself in his logic. He cancels the gaping abyss or formlessness in order to affirm the identity of the concept. In his defence of the Hegelian position in "Limit, Ground, Judgement... Syllogism: Hegel, Deleuze, Hegel and Deleuze," Jay Lampert argues that Deleuze reduces the Hegelian ground to the Leibnizian notion of convergence, when the ground is "the source of still more difference." 18 The problem for Deleuze is not that Hegel appears to have conceived of difference as sort of convergence as Leibniz had done, neither is the idea that the absolute realizes itself with ever more difference put into question by him, since the ground is indeed the rendering infinite of the concept, so requiring ever more differentiations. The point is that, the ground as "still more difference" does not save Hegel from a Deleuzean critique. It is instead the basis of such a critique. It is not enough to extend the ground in order to demonstrate how difference works on its terrain. What Hegel calls contradiction is radically reformulated in Deleuze's philosophy as the moment of differentiation, expressed in the questioning instance, what difference is there; a difference that pertains to the movement from one level of repetition to another. For Deleuze, difference does not "resolve itself" in the ground as it does in Hegel. It is primary, meaning that it is the moment of groundlessness showing itself in the ground as erecting the ground itself. The entirety of the process of erecting the ground from the perspective of groundlessness presents the difference; it is the singular event itself in the making. The so-called higher position for Deleuze does not involve "reaching the infinite" of contradiction, or raising difference to contradiction. What is this higher moment but the affirmation of absolute knowledge, the realization of the dialectical logic itself in the concept, in which the essence of the finite is said from the perspective of the infinite? 
There is a significant reversal of this moment in Deleuze's philosophy. This moment is not a preservation of what came before. It is not a raising up. It is a releasing in the highest affirmation in which the difference is made. This is why Deleuze claims that "difference is light, aerial and affirmative. To affirm is not to bear but, on the contrary, to discharge and to lighten."19 In other words, when we claim that Hegel seems to have closed the circle, or that he reduces difference rather than raising it up to a higher position in contradiction, we are arguing alongside Deleuze that the dialectical circle saves the whole in a "gigantic memory;" that the ground is the "power of memory" which carries "the average forms to infinity." 20 In the place of the selection of difference on the basis of re-presentation, Deleuze argues for a repetition that would affirm the "formless power of the ground." 21 In contrast to representation, "repetition is the formless being of all differences, the formless power of the ground which carries every object to the extreme 'form' in which its representation comes undone." 22 But doesn't this mean that difference is left undetermined? This is precisely what Lampert asks in the concluding his paper. He writes:

If each determination if already a difference, then making it different will not negate it. But does this mean that difference has no determinate content? If each determination were a general 'mixture' [...], then while the upside would be that identity [is] lost, the downside would be that so was difference. But if differences are indeed determinate, why not call them negative? After all, they would override boundaries, flee constraints, abstract from properties, become-other, etc. ${ }^{23}$

In The Logic of Sense (1969), Deleuze warns against this sort of interpretation of difference when noting:

What is common to metaphysics and transcendental philosophy is, above all, this alternative which they both impose on us: either an undifferentiated ground, a groundlessness, formless nonbeing, or an abyss without difference and without properties, or a supremely individuated Being and an intensely personalized Form. Without this Being or this Form, you will have only chaos. ${ }^{24}$

Deleuze is not satisfied with expressing difference under the concept. Neither is he willing to leave difference indeterminate. The difference made in the doubled affirmation, what he calls the eternal return, is the ground made from the perspective of groundlessness, not the other way around. It is a reversal, a kind of turning inside out of the surface, in which identity is said of difference, groundlessness as raising the ground, and determination as both determination and indetermination at once. Having highlighted that Hegel is according to Deleuze unable to do away with the vicious circle, since his dialectical logic cancels the gaping abyss, formlessness, let us 
return to the doubling of affirmation. As though addressing Hegel, Nietzsche writes in Thus Spoke Zarathustra:

\begin{abstract}
'Behold,' I continued, 'this moment! From this gateway, Moment, a long, eternal lane leads backward: behind us lies an eternity. Must not whatever can walk have walked on this lane before? Must not whatever can happen have happened, have been done, have passed before? And if everything has been there before-what do you think, dwarf, of this moment? Must not this gateway too have been there before? And are not all things knotted together so firmly that this moment draws after it all that is to come? Therefore-itself too? For whatever can walk - in this long lane out there too, it must walk once more. ${ }^{25}$
\end{abstract}

There are two affirmations in Nietzsche formulation of the eternal return: it is continuation and moment, the two being synonymous with the double affirmation of becoming and the being of becoming. The difficulty of articulating the eternal return as embracing these simultaneous temporalities is evident in Deleuze's colloquium on Nietzsche when he inquires:

How does one explain that [the eternal return] is both cycle and moment: on the one hand continuation; and on the other, iteration? One the one hand, a continuation of the process of becoming which is the World; and on the other, repetition, lightning flash, a mystical view on this process or this becoming? On the one hand, the continual re-beginning of what has been; and on the other, the instantaneous return of a kind of intense focal point, to a 'zero' moment of the will?26

There are two ways in which these two directions of the eternal return are explained, which, nevertheless amount to the same thing. In the first place, as Nietzsche writes, when one says "yes to a single moment [they] say yes to all of existence." 27 To say yes to a single moment, means not only to affirm that which has been, but to will it yet again without dwelling in the past. Listen to Heraclitus' dictum, there is no land in the ocean of becoming. This willing is always oriented towards the future, the moment is itself conceived as the creation of the world anew. This is tragic joy. Once a form has been found, it must be lost to the abyss, because a being that says yes to becoming, cannot will anything other than the continuation of such becoming. Therein is its ethical decision. The ring must be a broken one, lest we appropriate beings to not-being, which would be violent. Deleuze too joins continuation and moment together when arguing that the eternal return is the repetition of the future. All of time unfolds as a function of the caesura, being itself the moment that decenters the circle. How does Deleuze show this?

In joining peak and abyss, Nietzsche formulated a paradoxical logic in which chaos and necessity are both affirmed, their thought together being 
conditional upon the circle itself being a broken one. ${ }^{28}$ If amor fati or the love of destiny is affirmed in the eternal return, this is only from the perspective of a chance point that gathers the degrees of being in a supreme constellation. The chance point of pure affirmation is the "the celestial necessity that forces even chance events to dance in stellar formation." 29 Deleuze interprets Nietzsche's events as degrees of intensive quantities or differences, which, from one to the other, form the continuous variation of the constellation of being. This constellation is not presented all at once, but repeatedly differentiated from one degree to another, from one intensive difference through all the degrees which repeat one another. Each of these degrees of being as repetitions or virtual events as such, are themselves cuts in the continuity that also present, move toward, the actualized of the virtual in adjacent fields. In being bound to repeat that which is singular to a life, the repetition of the different degrees of being, is the in-itself of the past, the ground. Throughout Difference and Repetition Deleuze will refer to the presentment of the degrees of being as a sort of effect, "like an optical effect, or rather the erotic effect of memory itself." 30 Only once this constellation becomes a "freeze-frame", once it is exhausted, does a simulated sense become articulable (what Husserl will frame as copulative spontaneity). ${ }^{31}$ This freeze-frame is again discussed by Deleuze and Felix Guattari in What is Philosophy? (1991), with the two arguing that science "relinquishes the infinite, infinite speed, in order to gain a reference able to actualize the virtual. [...] In the case of science it is like a freeze-frame. It is a fantastic slowing down, and it is by slowing down that matter, as well as the scientific thought able to penetrate it with propositions, is actualized."32 Said in other words, the exhaustion of the constellation of events that compose the virtual give way to a simulated sense, an articulation of what an actual entity is. In The Logic of Sense, Deleuze rightly points out that such an articulation takes the form of the infinitive verb, which becomes conjugated with respect to individuals, persons, and cases. ${ }^{33}$ Here is it relevant to inquire, however, by what necessity "form" emerges from chaos, and not merely that it has emerged as such. A swift answer would be that it emerges by the same necessity that the whole of the constellation itself arises.

As that which unfolds the line or constellation of being, the eternal return is the formlessness which insinuates itself in the form that it creates. Once becoming is itself affirmed (the virtual actualized), the eternal return "comes back and flows back through all the modifications," showing itself as that which is repeated in all of the degrees of being, as their reason for differentiation. ${ }^{34}$ By being that which is repeated in each repetition of difference, it is, according to Deleuze, the differentiator that causes "chance events to dance in a stellar formation." This sort of re-turning has an intimate relation to questioning. As with Heidegger, Deleuze makes the question be the central point of the inversion of the look away from the tracing of the virtual elements and their lines of actualizations. The turn away from actualization with the exhaustion of the constellation, arises as 
the question what difference is there? For Deleuze, this question marks the movement from one repetition to another, but we could also say that it arises once the being of the past and actuals appear to present a sort of dualism with respect to which the status of the actual is put into question. The actual is not strictly speaking completely determined by the virtual elements presented in the being of the past, nor is it then merely that which is actualized; hence the emergence of the question, what difference is there, which would otherwise be what is the object $=x$. But the question what difference is there to which the higher instance of thought corresponds is precisely the question how does a being become, precisely because the question places us at the center of differentiation. It is with the questioning instance that the look is inverted, shedding light on the becoming of beings, which is, according Deleuze, "pure virtuality [that] no longer has to actualize itself, since it is a strict correlate of the actual with which it forms the tightest circuit." 35 This reversal of the look upon the virtual events anew marks the return of difference, the un-grounding of the ground, on the basis of which the continuation of the becoming of beings is open for affirmation. But doesn't the eternal return then lend its affirmation to the same form of becoming? Why does it dissolve the form in showing itself as the differentiator of the constellation? Here is where Deleuze's thought exposes the re-turning, thinking that which is supremely elusive:

There is eternal return in the third time (the repeated, the future, repeats itself): it is here that the freeze-frame begins to move once more, or that the straight line of time, as though drawn by its own length, reforms a strange loop which in no way resembles the earlier cycle, but leads into the formless, and operates only for the third time and for that which belongs to it. ${ }^{36}$

According to Deleuze, in tracing the field of virtual events we become equal to the potentials of the past, but the past or the second repetition only arises by virtue of that which is repeated each time, the future. This means that the repetition of the past happens "once and for all," it shall never return in its specific configuration. It is in this sense that everything which is said of becoming is contingent, it does not occur outside of the differential relations of living beings. As that which causes becoming to return, the eternal return, however, "returns for all times, for eternity." 37 What returns for all eternity is the yet-to-come, "the becoming-identical of becoming itself" on the basis of the different. 38 The identical as continuation is second principle, principle become, because it revolves around the different. This reversal is grasped by Deleuze as the pure event, an event which displaces the verb to be, all the while reinforcing the notion that the simulated sense articulated must itself be expressed as a becoming, which, in turn, itself as verb, displaces the identity of the present-being at hand. The ousting of the verb to be in the double sense is thus, effectively realized with Nietzsche's eternal return. 


\section{To and From the Virtual: The Double Sense of Becoming}

In Difference and Repetition, Deleuze argues that the present is a contraction of a certain level of the past, with respect to which the present always produces something novel. No two presents are identical, as each present is the maximal contraction of a different level of the past. The contractions of different levels explain why the instants of the first synthesis themselves differ. "What we live empirically as a succession of different presents from the point of view of active synthesis is also the ever-increasing coexistence of levels of the past within passive synthesis. Each present contracts a level of the whole." 39 The difference between the instants, then, manifests the coexistence of the different levels of the past actualized in the present. We can only reflect upon them as different in degree on the basis of this more profound difference of contractions, or repetitions, that take place in the being of the past as a whole. Conversely, if we install ourselves in the being of the past, the past "appears as the coexistence of circles which are more or less dilated or contracted, each one of which contains everything at the same time and the present of which it is the extreme limit." 40 Leaving aside the coexistence of circles for the moment, we notice that the past plays itself out at different levels. In fact, these different levels are already implied in the contraction of the past in the present, but the first repetition of the present and the second repetition do not have the same relation to difference. ${ }^{41}$ In the second repetition, difference is no longer traced from one instant to the next. It is instead there between the different levels of the past, along with the lines of actualization that the past appears to have given way to (that which is actualized by beings). Indeed, the present is a contraction of the extreme limit of the past, but the ground of the past is itself composed of different levels that replay the same story, theme, or most appropriately, a life, in varying degrees. The contraction of the past therefore consists of the tracing of the whole of the past which coexists with itself at varying levels. As Deleuze claims after Henri Bergson, to be installed in the past means repeating the same spiritual life at varying levels, from the most relaxed to most contracted degree of difference. By being installed in it, we do not actualize a maximal level straight away. There is a sort of presentation of the series of levels that are selected to form the maximal level of potential. To say that the past is presented is in a sense correct, since the ground of the past is populated by virtual images, singularized events, which demonstrate the continuous variation of the past. The past preserving itself in itself, or as repeated at different levels, shows us how the "manner in which each [past event] continues the whole life, but at a different level or degree on the basis of a past which was never present." 42 Or, as Deleuze also writes, "everything happens as if our memories were repeated an indefinite number of times in these thousands and thousands of possible reduction of our past life." 43 As mentioned earlier, the repetition of a life at difference levels is 
referred to as destiny by Deleuze, while the selection of the level played out defines our freedom. ${ }^{44}$ The choice of the level is nevertheless not decided from the perspective of the past. We turn towards the past with respect to the future.

Thus far I pointed out that the past is what is and that it replays a life, but what is this being of the past? Is the being of the past one and the same thing as my personal past, my life? It would be a mistake for us to assume that the being of the past is my personal memory, as this would reduce ontological duration to psychological duration, the virtual being part of the brain, or the duration of a single being. In Bergsonism (1988), Deleuze proposes that because there are indeed durations that exist outside of us simultaneously as our own, our consciousness cannot account for the way in which things experience duration. 45 Bergson claims that "there is some inexpressible reason in them which accounts for our inability to examine them at successive moments of our own duration." 46 But the idea that there are diverse durations at the same time as my own, does not in any way tell us that beings are merely closed in on themselves. If duration belongs to things as much as it is attributed to my consciousness, then, for Deleuze, psychological duration must open onto an ontological duration in which all beings would participate. ${ }^{47}$ In the place of several durations, we now have the single time of an ontological duration. The problem with ontological duration, however, is that beings continue to experience time in divergent ways. Deleuze, therefore, asks: "In what sense can one get beyond the ontological alternative of one/several?" 48 Since the being of the past is the condition of experience, we must show how there is a single time in which things participate, how they share a singular bloc of becoming, all the while giving way to divergent durations. Unravelling this complexity is a great challenge. Our primary question whether this past is my personal past demonstrates one of the illusions of the ground, a projection of my duration onto it. Such an interpretation appears to be plausible, especially because the ground gives way to divergent durations, one of which is my own. Deleuze seems to have resolved the problem of the one or several durations in Difference and Repetition. In Bergsonism, however, the problem is evident when Deleuze expresses the following reservation: "insofar as we are dealing with qualitative distinct fluxes, it may in fact be difficult to know whether or not the two subjects live and perceive the same time: We support unity, but only as the most 'plausible' idea." 49 This reservation is legitimate because once we have installed the qualitatively distinct fluxes, it is difficult to demonstrate that beings perceive the same time. In addition to this, even if we say with Bergson that the brain is part of the image, rather than constituting the virtual images themselves, it remains unclear how this past is not my personal past. Deleuze's framing of the problem shows us that he is carefully thinking through the relationship of the virtual and its diverging lines of actualization. Does actualization imply one and the same virtual for 
divergent beings? In what follows, I will outline how the dualism of the one/several can be overturned.

Allow me to briefly return to the multiple durations disclosed in the present. For Deleuze, these durations only appear to me because my duration is among others: "the flowing of the water, the flight of the bird, the murmur of my life form three fluxes; but only because my duration is one of them, and also the element that contains the two others. Why not make do with two fluxes, my duration and the flight of the bird, for example?"50 We cannot say that there are only two fluxes because their simultaneous existence implies that they are contained in a third duration. My duration makes it possible that I reflect on another that is reflected in my own. Their simultaneity is made possible by a third, meaning that my duration is reflected in another one that likewise contains the duration of the flight of the bird. "It is in this sense that my duration essentially has the power to disclose other durations, to encompass the others, and to encompass itself ad infinitum."51 But these coexisting durations in the present only gives us the outer envelope of this third duration, after its division has been actualized. According to Deleuze, if we install ourselves directly in the virtual, there is only a single time or constellation, the third, in which there are no longer distinct durations. There is a convergence upon the same one. The time of the virtual, then, as the condition of experience, is not my personal memory or the memory belonging to another being, but an impersonal time in which $a$ life unfolds. Deleuze noted that the ground in which beings participate, "no longer simply signifies my relationship with being, but the relationship of all things with being."52 But what is this relationship with being exactly? The virtual events that play out different levels of the past give us what is impersonal of a relation, or alternatively, being is itself the bloc of becoming is the non-relation of a relation, as that which makes the relation be what it is. What the repetitions of the past shows us, then, are the continuous variations of a relation; one that varies with respect to itself. The being of the past is a time shared in which beings are enveloped; the virtual is our other half, which cannot be in any sense actual or lived by beings. ${ }^{53}$ This other half which implicates us does not exist as such but subsists or insists in the present. This is precisely what the being of the past must be; it must form itself as that which is in-between. Only in this sense could we experience another being in relation to being. Of course, we do not experience the duration of another being, but experience another only by participating in that which is internal to both durations as their condition. Among others, Deleuze deploys the example of the orchid and the wasp so as to show this bloc of becoming that is in-between yet irreducible to the two: "The orchid seems to form a wasp image, but in fact there is a wasp-becoming of the orchid, an orchid-becoming of the wasp, a double capture since 'what' each becomes changes no less than 'that which' becomes. [It is] one and the same becoming, a single bloc of becoming." 54 
By differentiating, the virtual gives way to actualizations. In the being of the past, every repetition itself produces and has produced divergent lines of actualizations asymmetrical in nature.55 The entirety of the ground prepares the dissection, the splitting of the past into divergent lines of actualization with the maximal contraction being actualized in the present. But the lines of divergence move back and forth from the ground to the periphery, reflecting each level of the past, or the way in which the differentiation is developed in actualizations. ${ }^{56}$ The latest actualization reflects the maximal contraction, while previous lines of actualizations give us what might be called my personal past. What is so fascinating about Deleuze's past is precisely that each repetition is a cut in the fabric of the ground, at which point the past splits into two movements. In one direction, divergent lines are further developed in accordance with the capacity of each being, and give way to the actual in the present; an actual which is not the mere copy of the virtual. In the other direction, these diverging lines can be traced back to the centers of convergence of the past once the actualization has been made.57 "In both cases," Deleuze writes, "the pathways are the same; what matters is the direction one takes them in, towards divergence or convergence."58 By following one line toward divergence in order to shed light on the actual being, we see that this being is constantly displaced and differentiated with respect to itself. The diverging lines "show us the thing itself identical to its difference, internal difference identical to something." 59 If we move in the direction of the virtual away from the actualizations of living beings, these lines, now being three, converge or intersect upon the same event. Deleuze notes that, it is as though the

articulations of the real and [diverging] lines were relayed back and forth: the articulations of the real and [diverging] lines which at least reveal internal differences at the limit of their convergence, and conversely, [diverging] lines give us articulations of the real, e.g. the convergence of the three diverse lines, leading to the true distribution of what belongs to the subject and what belongs to the object. 60

In the course of actualization, the being of the past appears to produce the difference that is developed on each side of the divergent lines, in the object and in the subject, but it also simultaneously turns in on itself, so as to reflect the divergence as though in a mirror. The tracing of the past in the direction of the virtual, therefore, presents us with the continuity or becoming of the past, the way in which it calls forth a new present in the direction of the future. The being of the past is hence a passive synthesis of two dimensions: "it spits in two dissymmetrical jets, one of which makes all the present pass on, while the other preserves the past," or the passing of the present. ${ }^{61}$ In the process of tracing the ground, we not only see how it is that the present passes with the development of the lines of actualizations, but the formation 
of the past on its own terrain as a singular time in which divergent lines converge. With respect to the former, the passing of the present pertains to that part of the event actualized in it; what Deleuze also refers to as an effect in the present, preserved in the past as a singularized event.

Let us now take this line (later called the line of flight) in the other direction by turning towards the virtual, rather than tracing its actualization in the actual which is presented as convergence in the second synthesis. It must be kept in mind that the entirety of this tracing culminates in an event; it is the event as it becomes in two directions, its singularization and actualization as two sides of a surface, even while the workings of the past have been presented prior to taking up the pure event of the third time. When opening the discussion of the third synthesis of time, Deleuze evokes Plato's movement of the soul or learning, which involves a retrieval of what has been forgotten. In evoking Plato, Deleuze wants to emphasize the illusions that the ground is susceptible to if conceived of as operating by itself; by operating by itself, we mean that it constitutes the entirety of time. While Plato is the figure with whom the circular movement of the ground (model) and that which is grounded (the copies) is inaugurated, such illusions are, however, not delimited to Plato's pure past. They apply to the workings of the past in general. It is worthwhile noting that the circular relationship of the ground to that which is grounded installed from Plato onward, "elevates the principle of representation-namely, identity, which it treats as an immemorial model, and resemblance, which it treats as a present image: the Same and the Similar." 62 The past as model merely offers the image in accordance with which the resemblance of the copies becomes measurable. If we were to follow this formulation of the pure past, we could not make the claim that the living organism creates anything new, only that it distributes the model to different degrees.

This problem of circularity is not delimited to such a vision of the past. As we saw with the brief discussion of Hegel, transcendental philosophy likewise encounters it when it posits the being of the past as ground in relation to the present, or that which is grounded in it. This sort of illusion appears to be permitted by the "ambiguities of Mnemosyne, [or] was already implicit in the second synthesis of time," precisely because the events of the being of the past mark the centers of convergence of series; the centers around which two terms converge in a third, are the same centers which appear to be prolonged in lines of actualization.63 The second repetition reinforces the idea that the past moves in a circular fashion with respect to the present, and that the ground falls into what it grounds as the completed, because it appears as though its being is conditional upon the terms which implicate it. As Deleuze tells us, these repetitions

include difference, but include it only between the degrees or levels. [The second repetition] appears first in the form of the circle of the past coexistent in themselves [convergences]; then in the 
form of the circle of coexistence of the past and the present [convergence and division]; and finally in the form of a circle of the presents which pass and which coexist in relation to the object=x." 64

But it is not as though the past and the present move in a closed circle. On the one hand, to conceive them as moving in a closed circle is a philosophical error. On the other hand, the circle is dependent upon an affirmation; whether enough chance is affirmed in the organization of time in its entirety. It is this affirmation which is imperceptible in the circle, but is already everywhere dispersed in it because there is nothing like the Identity of the past, neither does the conditioned itself resemble what conditions it, or that which it is in relation to so as to become conditioned as such. Deleuze makes such arguments convincing only from the third synthesis of time. In order to transition away from the past, which is not primary in the order of time, we must remember that to ground is to determine the indeterminate, with the indeterminate already installing itself imperceptibly in the second repetition. As I have argued above, the continuum of the ground is "bent and must lead us toward a beyond, so the second synthesis of time points beyond itself in the direction of a third which denounces the illusion of the in-itself as still a correlate of representation." 65 It is the re-turning toward the virtual which splits the image in two. We take the direction of the future by way of the question. From the perspective of third repetition, we no longer trace the ground in relation to the grounded, but groundlessness as now infusing the ground as the reason behind the differentiation of beings.

The third repetition splits the image in two unequal halves. Deleuze presents this time as out of joint because the before of the being of the past along with the conditioned, and what comes after, do not coincide. There is something unequal introduced in the second repetition which cannot be made in conformity with it. The ground strangely bending in another direction after it culminates in a freeze-frame or a frozen image, is the opening up of the freedom of the future; the beginning of time as opening up the becoming-world yet again for another time. Deleuze, hence, writes that,

time out of joint means demented time or time outside of the curve which gave it a god, liberated from its overly simple circular figure, freed from the events which made up its content, its relation to movement overturned; in short, time presenting itself as an empty and pure form. Time itself unfolds (that is, apparently ceases to be a circle) instead of things unfolding within it (following the overly simple circular figure). 66

I have already argued how this image is split in two by discussing the continuity of becoming in relation to the caesura. The articulation of the third repetition as a pure order of time is a precise one, because, with it, we 
no longer have the complex of virtual events unfolding in time, but time itself unfolding as a function of the caesura. The caesura is the instant that disjoints time, or distributes the before and the after of time in such a way as to render events kinds of verbs or becomings, moving in two directions simultaneously. By borrowing Hölderlin's aphorism that time no longer rhymes, Deleuze wants to demonstrate that there is something unequal to the ground, which nevertheless configures it, all the while dissolving it.

Overturning its own ground, time is defined not only by a formal and empty order but also by a totality and a series. In the first place, the idea of a totality of time must be understood as follows: the caesura, of whatever kind, must be determined in the image of a unique and tremendous event, an act which is adequate to time as a whole. ${ }^{67}$

According to Deleuze, the pure event of the third repetition draws together the other syntheses of time, which are conceived now from the perspective of the caesura. It draws them together, however, without necessarily doing away with their distinct operations. It is better to say, then, that the other syntheses are explained from the perspective of the third, because the third is that which "makes" the difference. This is what Deleuze means when he argues that, "in a certain sense, the ultimate repetition, the ultimate theatre, therefore encompasses everything; while in another sense it destroys everything; and in yet another sense selects among everything." 68 Along with the repeater of the present and the repetition of the past, there is that which is repeated in them; the eternal return of the future. The eternal return unfolds the circle so as to form a straight line, or raises the ground never to see the same return, by rendering repetition for itself adequate to difference in-itself. Since the third repetition distributes difference, the other repetitions arise in relation to it, while also being displaced by it. Only difference initself returns in the empty form of time. The other syntheses are displaced by it because the eternal return introduces a differentiation that each time distributes the being of the past anew, giving way to the creation of the novel in the present. This each time means that the other repetitions do not return, only the differentiation that disjoints time returns. It returns as that which dissolves the ground into groundlessness. It is the essential formlessness which insinuates itself in every form, thereby, resisting the appropriation of the event in representational models towards which it tended.

I have argued that the eternal return displaces the being of the past because it is already involved in it. With the culmination of the virtual events of the past, the line reverses itself, illuminating the pathway anew, in reverse, showing the third repetition to have been there all along, configuring the past itself. To begin with, the third repetition is disguised in the events of the being of the past, which, in accordance with the operation of the past, become centers of convergence. But these centers of convergence 
bear the differentiation, since the being of the past does not itself resemble, it is not the same as the divergent series of actualizations, neither do the events that configure it, the levels of the past, bear the same intensity, even though they replay a complex theme, a life, a rhythm. ${ }^{69}$

This is our first hint of differentiation. Deleuze refers to such a disguise of the third in the second repetition as the dark precursor. The dark precursor is the disguised differentiation, or that which makes the difference, in the second synthesis of time. The concept of the dark precursor can appear mysterious if we do not grasp the simplicity of the eternal return, or more importantly, if we do allow that time unfolds as a function of the caesura, because of which every determination carries along with it indetermination. So why is the precursor dark in the second repetition? The precursor is dark in the second repetition, because it is "covered by the phenomena it induces within the system"; it is covered over primarily by the centers of convergence that compose the past, which such centers of convergence being the creation of a world..$^{70}$ But the point is that the second repetition is induced from the perspective of the caesura, even if this is not apparent to begin with. In reverse, each center of convergence will be shown as bearing a differentiation that leads to a divergence. Each repetition will become disjointed, showing now only difference in-itself. When traversing the entirety of the transcendental field, the difficult question is always whether it is divergence or convergence that is primary. Deleuze's most radical argument is that divergence instigated by differentiation is primary in the order of time. It is, as we have noted, that which gives birth to timenot only by raising events to the surface, but in dissolving the ground with the difference made. With the being of the past "the dividing in two, this differentiation, did not reach completion [...] because time rolled itself up, and its two aspects relaunched themselves into the circuit whose poles they recharged while blocking up the future."71 When tracing the theatre of the virtual, we do not simply move through the different levels which unfold in time. We move back and forth, from the centers of convergence, the virtual events, along the lines of actualization, and back again, until the entirety of the circuit (of the virtual and the actual) plays itself out or plays out a becoming.

Now, in contrast, the dividing in two [of the virtual and the actual] can come to completion, but precisely on the condition that one of the two tendencies leaves the crystal, through the point of flight. [...] Everything that has happened falls back into the crystal and stays there: this is all the frozen, fixed, finished-with and overconforming roles that the characters have tried in turn. ${ }^{72}$

What exits this crystal, thereby shattering or fracturing the point of view, is the differentiation of the virtual, since it is in itself unequal to the past on the whole. It is released from imprisonment in the other repetitions, reverses itself, and in the process dissolves them, never to see them return in the 
same configuration. The unequal emerges, from the theatre in which the combination of the past is configured, as the future: "It creates this future as a bursting forth of life. [...] One leaves the theatre to get to life, but one leaves imperceptibly, on the thread of the stream, that is, of time. It is by leaving it that time gives itself a future."73 The thread traced is the ultimate differentiation that opens onto the future. The eternal return of difference is the highest object of affirmation, because therein lies our unbound joy together with the greatest freedom: to begin the story of time anew with the dissolution of time. Hölderlin captures the dissolution of time and the birth of a life anew essential to events, when writing the following:

Thus dissolution as necessity, from the viewpoint of ideal memory, becomes as such the ideal object of a newly unfolded life, a look back at the path that had to be traversed from the beginning of the dissolution up to where out of this new life a memory occurs of what was dissolved, and out of that, as explanation and unification of the gap and the contrast that occurs between what is new and the past, the memory of the dissolution can follow. The ideal dissolution is fearless. The beginning-and endpoint are already posited, found, secured; therefore this dissolution is also more certain, more irresistible, bolder; and thus it presents itself as what it actually is, as a reproductive act whereby life runs through all of its points and, to acquire the sum total, lingers over none, dissolves itself in each, to produce itself in the next. ${ }^{74}$

\section{Concluding Thoughts on Events}

In this paper I have explored the virtual and the actual, particularly through Deleuze's philosophy of time, so as to focus in on what is at the heart of events, what it is that allows us to oust the verb to be through the philosophical concept of event. In the first part of this paper, I placed the emphasis on the way in which Nietzsche, as a thinker of univocal being, contributes to Deleuze's articulation of being as becoming. Such an articulation, I argued, is dependent on the eternal return being both an instant and a continuation of the stream of becoming. If the eternal return is, together, instant and a singular becoming, or more to the point, a variation in the stream of becoming, then, a singular event enfolds precisely that, the instant of differentiation, which makes of it a becoming that moves in two directions simultaneously; the event is always, as Deleuze tells us, that which happened and what is about to happen. To grasp these two directions, or lines that compose the nature of events, I took up the relation of the actual and the virtual, particularly by dealing with some of the core complexities of the three syntheses of time. I argued that in there are two paths through which the complex entanglement of the actual and the virtual can be approached, and these two paths, away and toward the virtual, 
happen at once and indeed oust the verb "to be" in a double sense; on the one hand, the present-being is ousted in the same process it is constituted, and in the other direction, the being of the past, or what is, is perpetually dissolved with the being of becoming which introduced the differentiation as the heart of a singular event. Or, alternatively, the actualization of the virtual on the one hand, and the dissolution of the actual object as it becomes indiscernible from the virtual on the other, are two paths laid out at once, even while the sort of process implied by each is different. Again, the asymmetrical processes demonstrate that in one direction the event is actualized, while in the other, toward undoing, it is counter-actualized, or that which cannot be actualized as such. Perhaps the most important theme discussed in this paper is the role that the differential relation plays in Deleuze's philosophy of events. This theme prompts us to ask how it is that the third synthesis of time serves as a kind of selective test whereby actual beings become indiscernible from the virtual when affirmed as events. This does not mean that actual beings are inconsequential or have no role to play in creating whatsoever, but precisely the opposite. To affirm a being in its becoming, as event, is the ethics of events. It is to dissolve a world, a world which is not something external, above, or beyond, but a bloc of becoming, so as to make it anew at a higher level of intensity. It is to breathe new life into it, again.

${ }^{1}$ Deleuze, Negotiations (New York: Columbia University Press, 1995), 141

2 Peter Hallward, Out of this World (New York: Verso, 2006), 139

${ }^{3}$ The question what difference is there, along with counter-actualization has been explored by Constantin Boundas in Gilles Deleuze: The Intensive Reduction (New York: Continuum, 2009).

${ }^{4}$ Thus far, there have been only three studies published on Deleuze's engagement with Husserl, J oe Hughes' Deleuze and the Genesis of Representation (New York: Continuum, 2011), Alain Beauileu's "Edmund Husserl" in Deleuze's Philosophical Lineage (Edinburgh: Edinburgh University Press, 2009), and "The Sense of the Transcendental Field" with the Journal of Speculative Philosophy in which the notion of copulative spontaneity is discussed.

${ }^{5}$ Whitehead, Process and Reality: An Essay in Cosmology (New York: The Free Press, 1978), 23.

${ }^{6}$ Deleuze and Guattari in What is Philosophy?. trans. Hugh Tomlinson and Graham Burchell (New York: Columbia University Press, 1994), 59.

${ }^{7}$ In Difference and Repetition, trans. Paul Patton (New York: Columbia University Press, 1994), 40.

For a further discussion on the Nietzschean 'correction' of Spinoza see Simon Duffy's The Logic of Expression Quality, Quantity and Intensity in Spinoza, Hegel and Deleuze. (Burlington: Ashgate, 2006). 
${ }^{8}$ While Heidegger puts forth this question, Michael Haar points out that he does not to put forth an adequate response to it. See Michael Haar's chapter, "The Overturning of Platonism and the New Meaning of Appearance," in Nietzsche and Metaphysics (Albany: State University of New York Press, 1996).

${ }^{9}$ Haar, Nietzsche and Metaphysics, 47.

10 Ibid., 49

11 Ibid., 34 (see endnote 48).

12 Nietzsche, "Philosophy in the Tragic Age of the Greeks" (1873), 107

13 Ibid. , 106

${ }^{14}$ Ibid., 111

15 Ibid., 113

${ }^{16}$ Deleuze, Nietzsche and Philosophy (New York: Columbia University Press, 2006), 23-4; emphasis added.

${ }^{17}$ Many authors have explored what Deleuze calls becoming, including Zourabichvili in Deleuze: A Philosophy of the Event. trans. Kieran Aarons (Edinburgh: Edinburgh University Press, 2012). The distinction between those texts and the study at hand is that I stress firstly the doubling of becoming and the way in which the verb 'to be' is displaced. I show that this sort of displacement is central to understanding the nature of events. The second difference is that I explore, now from the perspective of such a displacement, the becoming of beings themselves, which I claim is central to the ethic of the event.

18 Jay Lampert “Limit, Ground, Judgement... Syllogism: Hegel, Deleuze, Hegel and Deleuze," 1 (unpublished manuscript) Published manuscript can be found in Karen Houle and Jim Vernon's (eds) Deleuze and Hegel Together Again for the First Time (Evanston: Northwestern University Press, 2013).

${ }^{19}$ Gilles Deleuze, Difference and Repetition, 54.

20 Ibid. , 50

21 Ibid. , 57

22 Ibid.

${ }^{23}$ J ay Lampert “Limit, Ground, J udgement... Syllogism: Hegel, Deleuze, Hegel and Deleuze," 13

${ }^{24}$ Deleuze, The Logic of Sense, 106

25 Nietzsche, "This Spoke Zarathustra" in The Portable Nietzsche (London: Penguin Books, 1982), 270; emphasis added.

${ }^{26}$ Deleuze, "On the Will to Power and the Eternal Return," in Desert Islands (Minneapolis: University of Minnesota Press, 2004), 121.

${ }^{27}$ Haar, Nietzsche and Metaphysics, 30.

28 Ibid., 33 Haar writes that: "The inclusion of Chaos in the necessity of the circle does not constitute a synthesis or reconciliation in the manner of Hegel: chance and disorder are not 'surpassed' by, but gathered into, the perfect circle being defective in its very essence." 
${ }^{29} \mathrm{lbid}$.

${ }^{30}$ Deleuze, Difference and Repetition, 57, 88.

${ }^{31}$ In Difference and Repetition, Deleuze is still unsure what to call this sense. He refers to in different ways, as an effect, as a sign, as a simulated sense in relation to ontological sense, as Idea and as complex theme.

32 Deleuze and Guattari in What is Philosophy?. trans. Hugh Tomlinson and Graham Burchell (New York: Columbia University Press, 1994), 118.

${ }^{33}$ Ibid., 215; For a consideration of the relationship of sense to persons, individuals, and cases in The Logic of Sense, see Sean Bowden's The Priority of Events: Deleuze's Logic of Sense. (Edinburgh: Edinburgh University Press, 2011).

${ }^{34}$ Deleuze, Desert Islands. trans. Michael Taormina (Minneapolis: University of Minnesota Press, 2004), 123; minor changes to the original text.

${ }^{35}$ The translator of "The Actual and the Virtual" Eliot Ross Albert elaborates on this "inner circuit" when writing that this circuit "is what Bergson describes as the "moment when the recollection...is capable of blending so well with the present perception that we cannot say where perception ends or where memory begins."

${ }^{36}$ Deleuze, Difference and Repetition, 297.

37 Ibid.

${ }^{38}$ Ibid., 41

39 Ibid., 83; emphasis removed.

${ }^{40}$ Deleuze, Cinema 2: The Time-Image (Minneapolis: University of Minnesota Press, 2007), 98.

${ }^{41}$ See chapter 3 of Deleuze's Difference and Repetition. For a discussion of the past, I find J ay Lampert, Deleuze and Guattari's Philosophy of History (New York: Continuum, 2006) to be useful, while for a study of the living present, also see James Williams' Gilles Deleuze's Difference and Repetition: A Critical Guide and Introduction (Edinburgh: Edinburgh University Press, 2003). These studies are quite useful for orienting us, but the problematic, the relationship of the actuals and virtual posited as an issue in the articulation of event, here under consideration is different from the ones these authors have posed.

${ }^{42}$ Deleuze, Difference and Repetition, 83.

${ }^{43}$ Deleuze, Desert Islands, 29.

${ }^{44}$ Bergson refers to these levels as degrees of freedom in Matter and Memory (New York: Dover Publications, 2004), 294.

${ }^{45}$ Deleuze, Bergsonism. trans. Hugh Tomlinson and Barbara Habberjam (New York: Zone Books, 2006), 48.

${ }^{46} \mathrm{Ibid}$., emphasis added.

${ }^{47}$ Ibid., 48-9.

48 Ibid. , 48.

${ }^{49}$ Ibid., 83. 
50 lbid., 80.

51 lbid.

52 Ibid. , 77.

53 Ibid., 83-4.

${ }^{54}$ Gilles Deleuze \& Claire Parnet, Dialogues II. trans. Hugh Tomlinson and Barbara Habberjam (New York: Columbia University Press, 2007), 2.

${ }^{55}$ Deleuze, Bergsonism, 42-3.

56 Ibid., 95.

${ }^{57}$ Deleuze, Desert Islands, 32.

58 Ibid., 34.

${ }^{59}$ Ibid.

${ }^{60}$ Ibid., 38.

${ }^{61}$ Deleuze, Cinema 2: The Time-Image, 81.

62 Ibid.

${ }^{63}$ Ibid.

64 Ibid. 292.

65 Ibid., 88

${ }^{66}$ Ibid., emphasis added.

67 Ibid., 89.

68 Ibid., 293.

69 The complex theme which consists of singularities, virtualities, events, can be conceived from two different perspectives, the past or the future. In the tracing of the past they are centers, or points of convergence of the two series, while with respect to the future they are points of divergence, or a differentiation which is made in the tracing of the past. Each singularity is produced by differentiation because of which the two series, terms or beings diverge. Nevertheless, this divergence in the process of actualization is reflected back on the virtual image and becomes a point of convergence where the lines intersect. See Deleuze's discussion of factual lines in Bergson's philosophy in Desert Islands.

70 Deleuze, Difference and Repetition, 120.

${ }^{71}$ Deleuze, Cinema 2: The Time-Image, 88

$72 \mathrm{lbid}$.

${ }^{73} \mathrm{lbid}$.

74 Holderlin quoted in Nancy, The Birth to Presence. trans. Brian Holmes and others (Stanford: Stanford University Press, 1993), 73 